\title{
Essential oil of Rosmarinus officinalis L. from West Highlands of Algeria: Chemical characterization and in vitro antifungal activity against Fusarium oxysporum f. sp. albedinis
}

\author{
Zakaria Boukhobza ${ }^{1}$, (D) Noureddine Boulenouar ${ }^{1,2, *}$, (D) Abdelkrim Cheriti ${ }^{1}$ and (D) Zohra Kadri ${ }^{2}$
}

${ }^{1}$ Phytochemistry and Organic Synthesis Laboratory, Tahri Mohamed University, 08000, Bechar, ALGERIA

${ }^{2}$ Department of Biological Sciences, Institute of Science, Nour Bachir University Center, 32000, El-Bayadh, ALGERIA

*Corresponding author. Email: noureddine.boulenouar@gmail.com

Submitted: 05.04.2021; Accepted: 14.07.2021

\begin{abstract}
Rosmarinus officinalis is a well-studied species; however, $R$. officinalis essential oil (EO) from West highlands of Algeria was not investigated chemically and biologically. In this context, chemical composition of $R$. officinalis EOs obtained from leaves and stem were determined by GC/MS analysis and their antifungal activity against Fusarium oxysporum f. sp. albedinis (Foa) were evaluated. The GC/MS analysis indicated that monoterpenes were the dominant class of compounds in both leaves and stem (oxygenated $84.9 \%, 52.4 \%)$ and hydrocarbons (12.2\%, $8.4 \%$ ), respectively. Among them, 1,8-cineole was the main component (leaves: $54.4 \%$, stem: $29.7 \%$, which classifies these EOs as 1,8-cineole chemotype. The in vitro antifungal activity of Eos was evaluated through micro-atmosphere and direct contact methods. Best inhibitory activity against Foa was determined after 7-day incubation using direct contact method by relative growth reduction ( $R G R=0.398$; $R G R=0.383$ ) with EOs from leaves and stem, respectively.
\end{abstract}

Keywords: Essential oil, Rosmarinus officinalis, antifungal, fusariosis, GC-MS analysis

\section{Introduction}

The worldwide interest in the use of medicinal plants has been growing, and its beneficial effects being rediscovered for the development of new drugs (Andrade, et al., 2018). Essential oils (EOs) are known to have various bioactivities (antibacterial, antifungal etc.). Consequently, studies on their biological activities have become important (Shaaban, et al., 2012).

Rosmarinus officinalis species (syn.: Salvia rosmarinus Schleid, $R$. angustifolius Mill., $R$. communis Noronha) from Lamiaceae family, commonly known as 'Lazir' is an evergreen plant typical of the Mediterranean region. It is widely used in the Algerian ethnopharmacopoeia as a spice and for the treatment of various diseases such as digestive troubles, gallbladder disorders, cephalic pains, headaches, migraines, colic, diarrhoea, cough and broncho-pulmonary infections (Cheriti, et al., 1995; Cheriti, 2000).

Despite the huge number of studies on $R$. officinalis, the most focused on phytochemistry then on biological activities. The studied biological activities were interested principally to human health (antimicrobial, insecticidal, antioxidant, aromatherapy) (Andrade, et al., 2018; Durak, et al., 2016; Mekonnen, et al., 2016; Isikber, et al., 2006); less was concerned by Fusarium oxysporum (phytopathogen) (Mekonnen and Manahile, 2017; Ozkan and Chalchat, 2008). R. officinalis EOs from Algeria were found to be rich in 1,8-cineole and camphor. In addition, these EOs presented many biological activities such as antibacterial effect against human pathogenic bacteria (Boutekedjiret, et al., 1998; Djeddi et, al., 2007; Boutabia, et al., 2016).

Fusarium oxysporum f. sp. albedinis (Foa) is the causal agent of lethal disease of date palm called Bayoud. We have studied Bayoud disease for many years (Boulenouar, et al., 2009; Boulenouar, et al., 2011; Boulenouar, et al., 2012; Boulenouar, et al., 2014; Belhi, et al., 2020; Ghazi, et al., 2020); but till now there 
is no efficient treatment. The aim of this study is the investigation of antifungal effect of $R$. officinalis EO on phytopathogen fungus Foa. To the best of our knowledge, this is the first time that EO of $R$. officinalis from Algerian West highlands was investigated on phytochemical level and as potential antifungal agent against Foa.

\section{Materials and Methods}

\section{Plant material and essential oil extraction}

Aerial parts of $R$. officinalis were collected from West highlands (El-Bayadh, Algeria, Latitude: $33^{\circ} 40^{\prime} 49^{\prime \prime} \mathrm{N}$; Longitude: $1^{\circ} 01^{\prime} 13^{\prime \prime} \mathrm{E}$; Altitude: $1313 \mathrm{~m}$ ) during March 2018. The species was identified, and a voucher specimen is kept at Phytochemistry and Organic Synthesis Laboratory under $N^{\circ}$ CA99/11. The leaves and stem were separated, washed, dried in shade, then grinded until obtaining a fine homogenous powder.

The $R$. officinalis essential oil was obtained from dry plant material (100 g) by hydrodistillation using a Clevenger apparatus for $3 \mathrm{~h}$, in accordance with the 3rd Edition of the European Pharmacopoeia cited by Bruneton (1999). The process was repeated five times to get a sufficient amount of EO for antifungal tests and chemical analysis. The obtained oil was dried over anhydrous sodium sulphate and stored in hermetically closed small vials at $4^{\circ} \mathrm{C}$ until use.

\section{GC-MS analysis}

Gas chromatographic (GC) analysis was performed on a Perkin Elmer Clarus 680 gas chromatograph equipped with an FID and fitted with a fused-silica Rtx-5MS capillary column ( $30 \mathrm{~m} \times 0.25 \mathrm{~mm}$, ID $0.25 \mu \mathrm{m}$ film thickness). The analytical conditions were: Carrier gas was $\mathrm{He}(1.0 \mathrm{~mL} / \mathrm{min})$, injector and detector temperature were $280^{\circ} \mathrm{C}$. The temperature program used was $4 \mathrm{~min}$ isothermal at $70{ }^{\circ} \mathrm{C}$, increased to 180 ${ }^{\circ} \mathrm{C}$ at a rate of $4{ }^{\circ} \mathrm{C} / \mathrm{min}$, then increased to $240^{\circ} \mathrm{C}$ at a rate of $10^{\circ} \mathrm{C} / \mathrm{min}$ and ending with a $10 \mathrm{~min}$ at $300^{\circ} \mathrm{C}$. Samples were injected by splitting and the split ratio 1:5. The relative amounts of the individual components found in the oil are based on the GC peak areas obtained (FID response).

The GC/MS analysis was performed on Perkin Elmer Clarus 680 gas chromatograph, interfaced with Clarus SQ $8 \mathrm{~T}$ mass spectrometer, operating at electron impact of $70 \mathrm{eV}$ with an ion source temperature at $250^{\circ} \mathrm{C}$, scan mass range of $30-300 \mathrm{~m} / \mathrm{z}$ at a sampling rate of $0.5 \mathrm{scan} / \mathrm{s}$. A fused-silica Rtx- $5 \mathrm{MS}$ capillary column ( 30 $\mathrm{m} \times 0.25 \mathrm{~mm}$, ID $0.25 \mu \mathrm{m}$ film thickness was used under the same conditions as those used for gas chromatography analysis as described above. The EOs component identification from the GC/MS spectra was confirmed by comparison of mass spectral fragmentation patterns with the computer library (NIST MS Library), and verified by comparison of their retention indices, determined relatively to the retention times of a $n$-alkanes homologous series (C4-C40) of the identified compounds with literature (Adams, 2007; Babushok, et al., 2011; Benabed, et al., 2017; Boukhobza, et al., 2020).

\section{Antifungal test}

\section{Fungal strain}

The fungal strain used in this study is Fusarium oxysporum f. sp. albedinis. It was obtained from the Technical Institute for Development of Saharan Agronomy (TIDSA), Adrar, Algeria. It was identified and a voucher specimen was stored at Phytochemistry and Organic Synthesis Laboratory under $\mathrm{N}^{\circ}$ FoaPOSL/2011/01. Preparation of Foa culture was realized as described by Boulenouar et al. (2012). 


\section{Procedure}

Micro-atmosphere method. A 10mm diameter mycelial disc taken from 7 days culture of Foa was deposited upside-down in the center of PDA medium. Four volumes of EO $(10,20,30,40 \mu \mathrm{L})$ were spread on the lids of the Petri dishes (85mm diameter). PDA inoculated with Foa and without EO was used as a negative control. The observation of the results was carried out after incubation for 7 days and 10 days at $25 \pm 1{ }^{\circ} \mathrm{C}$. The tests were performed with three repetitions $(n=3)$ (Stupar et al., 2014).

Direct contact method. Four volumes of the EO $(10,20,30,40 \mu \mathrm{L})$ were spread on PDA medium (85mm diameter Petri dishes). A 10mm diameter mycelial disc taken from 7 days Foa culture was placed upsidedown in the center of the PDA medium. The negative control was performed with PDA medium inoculated with Foa and without EO. The observation of the results was carried out after incubation for 7 days and 10 days at $25 \pm 1{ }^{\circ} \mathrm{C}$. The tests were performed with three repetitions $(n=3)$ (Ozkan and Chalchat, 2008).

\section{Evaluation of antifungal activity}

Antifungal activity was evaluated using: growth rate (GR), percentage of growth inhibition (Inhib\%) and relative growth reduction (RGR). GR represents the speed of mycelium growth as millimeter per day (mm/day) (Kibar and Piksen, 2011). Inhib\% was calculated using the following formula: Inhib\% $=$ [(DC$\mathrm{DT}) / \mathrm{DC}] \times 100$. Where $\mathrm{DC}$ and DT are the average diameters $(\mathrm{mm})$ of fungal growth from control and treatment samples, respectively (Ozkan and Chalchat, 2008). RGR (\%.mm $\mathrm{mm}^{-1} \cdot \mu \mathrm{L}^{-1}$ ) evaluation takes in consideration the size of inoculums and quantity of analysed substance in the antifungal activity. It was calculated using the following formula: RGR = Inhib\% / (In $\times$ V). Where: "Inhib\%" is the percentage of growth inhibition (\%) calculated as cited above, "In" is the diameter $(\mathrm{mm})$ of mycelial inoculum from fungi culture, " $\mathrm{V}$ " is the volume $(\mu \mathrm{L})$ of EO used in treatment. No substance has been reported effective on Fusarium oxysporum f. sp. albedinis to be used as positive control. The negative control was test passed all protocol without using essential oils.

\section{Experimental design and data analysis}

The experimental design used in this study was factorial experiment. All experiments were conducted in triplicate. The significance of activities had been analysed with ANOVA test. Correlation between different factors was tested. The probability " $P$ value" less than 0.05 was considered significant $(\alpha=5 \%)$.

\section{Results and Discussion}

\section{Chemical composition of $R$. officinalis EO}

The green yellowish EO yield from leaves was significantly higher $(2.17 \pm 0.02 \%)$ than from stem $(0.98 \pm 0.01$ $\%)$, which is in accordance with the limits cited by Jawad et al. (2018). The extraction yield can be affected by many factors (seasonal and geographic conditions, distillation technique, harvest period...) (Rao, et al., 2014; Singh, et al., 2014; Kumar, et al., 2016). A total of 21 and 19 compounds representing $98.8 \%$ and $68.3 \%$ of the total EO were identified in leaves and stem, respectively. The chemical composition of the EOs were presented in Table 1. The components were listed in order of their elution on the Rtx-5MS capillary column.

The oxygenated monoterpenes were the dominant class of compounds in both leaves and stem (84.9\%, $52.4 \%)$, respectively. The 1,8 -cineole $(54.4 \%, 29.7 \%)$ was the main constituent, followed by camphor (10.1\%, 7.9\%), $\alpha$-terpineol $(7.6 \%, 5.6 \%)$ and borneol $(5.5 \%, 4.0 \%)$, respectively. 
The EOs of $R$. officinalis were found to contain six monoterpenes hydrocarbons (leaves: $12.2 \%$, stem: 8.4 $\%$ ), of which $\alpha$-pinene (leaves: 5.5\%, stem: $4.0 \%$ ) was the most represented component. In addition, EOs from both parts contains lower amounts of sesquiterpene (leaves: $1.4 \%$, stem: $7.4 \%$ ). When compared with leaves EO, higher amount of caryophyllene oxide (5.4\%) was measured in the stem EO. It's probably due to change of cytological, biochemical and physiological activities within organs (Zaouali, et al., 2013), and the importance of leaves as a centre of volatile compounds production in the plant (Boix, et al., 2011). In accordance with the richness of leaves in terms of volatile compounds, in this study, yield of leaves EO (98.8\%) was detected higher than that of stem EO (68.3\%) (Boix, et al., 2011).

Table 1. Chemical composition of the $R$. officinalis essential oil

\begin{tabular}{|c|c|c|c|c|c|}
\hline \multirow{2}{*}{$\mathbf{N}^{\circ}$} & \multirow{2}{*}{ Compounds } & \multirow{2}{*}{$\mathbf{R I}^{\mathbf{a}}$} & \multirow{2}{*}{$\mathbf{R} \mathbf{I}^{\mathbf{b}}$} & \multicolumn{2}{|c|}{ Content (\%) } \\
\hline & & & & Leaves & Stem \\
\hline 1 & $\alpha$-Pinene & 931 & 932 & 5.5 & 4.0 \\
\hline 2 & Camphene & 946 & 946 & 2.6 & 1.8 \\
\hline 3 & $\beta$-Pinene & 976 & 974 & 3.1 & 2.0 \\
\hline 4 & $\alpha$-Terpinene & 1016 & 1014 & 0.3 & $\operatorname{tr}^{\mathrm{c}}$ \\
\hline 5 & 1,8-Cineole & 1030 & 1026 & 54.4 & 29.7 \\
\hline 6 & $\nu$-Terpinene & 1059 & 1054 & 0.5 & 0.4 \\
\hline 7 & Sabinene hydrate & 1068 & 1065 & 0.1 & - \\
\hline 8 & $\alpha$-Terpinolene & 1089 & 1086 & 0.2 & 0.2 \\
\hline 9 & Linalool & 1103 & 1095 & 4.0 & 2.8 \\
\hline 10 & Camphor & 1144 & 1141 & 10.1 & 7.9 \\
\hline 11 & Borneol & 1170 & 1165 & 5.5 & 4.0 \\
\hline 12 & Terpinen-4-ol & 1180 & 1174 & 1.6 & 1.3 \\
\hline 13 & $\alpha$-Terpineol & 1193 & 1186 & 7.6 & 5.6 \\
\hline 14 & Verbenone & 1212 & 1204 & 0.5 & 0.4 \\
\hline 15 & Bornyl acetate & 1289 & 1284 & 1.2 & 0.8 \\
\hline 16 & Carvacrol & 1306 & 1298 & 0.1 & 0.1 \\
\hline 17 & Methyl eugenol & 1405 & 1403 & 0.1 & - \\
\hline 18 & $\beta$-Caryophyllene & 1421 & 1417 & 0.8 & 1.9 \\
\hline 19 & $(E)$-Geranylacetone & 1453 & 1451 & 0.1 & 0.1 \\
\hline 20 & $\alpha$-Humulene & 1455 & 1454 & 0.2 & 0.1 \\
\hline \multirow[t]{7}{*}{21} & Caryophyllene oxide & 1589 & 1583 & 0.5 & 5.4 \\
\hline & & & Monoterpene hydrocarbons & 12.2 & 8.4 \\
\hline & & & Oxygenated monoterpenes & 84.9 & 52.4 \\
\hline & & & Sesquiterpene hydrocarbons & 1.0 & 2.0 \\
\hline & & & Oxygenated sesquiterpenes & 0.5 & 5.4 \\
\hline & & & Others & 0.2 & 0.2 \\
\hline & & & Total & 98.8 & 68.3 \\
\hline
\end{tabular}

${ }^{a}$ Retention indices on Rtx-5MS column. ${ }^{b}$ Retention Indices obtained from literature (Adams 2007, Babushok et al. 2011). ${ }^{\mathrm{C} T r a c e}$ amount $<0.01$

The qualitative composition of EO from both parts was similar, but a marked quantitative difference was observed, which may be attributed to the growth phase of the plant, as it's well known that chemical variability may be related with different vegetative phases of the plant (Barra, 2009). Many studies have 
been carried out on the chemical composition of different samples of $R$. officinalis from different Mediterranean geographical regions revealing that chemical composition and percentage vary depending upon the plant parts, vegetative phases, extraction methods and environmental and growing conditions (e.g. seasonal and geographical variations, soil composition) (Carvalho, et al., 2005; Figueiredo, et al., 2008; Zaouali, et al., 2013; Andrade, et al., 2018).

According to previous studies, 1,8 -cineole ranging from 57.7 to $11.0 \%$, camphor from 36.7 to $7.9 \%$ and $\alpha$ pinene from 24.7 to $5,7 \%$, are the most represented components in all samples of $R$. officinalis EO from Mediterranean region : Algeria (Fellah, et al., 2018), Egypt (Fadel \& El-Massry, 2000), France (Chalchat, et al., 1993), Italy (Napoli, et al., 2010; Serralutzu, et al., 2020), Lebanon (Diab, et al., 2002), Morocco (Chalchat, et al., 1993; Rahmouni, et al., 2019), Portugal (Mata, et al., 2007), Spain (Chalchat, et al., 1993; Salido, et al., 2003), Tunisia (Hcini, et al., 2013; Zaouali, et al., 2013) and Turkey (Celiktas, et al., 2007; Ozcan \& Chalchat. 2008).

The EO extracted from $R$. officinalis collected from El-Bayadh (Algerian West highlands) was characterized by high content of 1,8-cineole, which classifies it as 1,8-cineole chemotype according to the classification of Napoli et al. (2010). It has been reported that altitude affects the chemical composition of EOs in many plant species (Barra, 1990). Concerning R. officinalis EOs, Sabbahi et al. (2020) has demonstrated that only the major constituent (1,8-cineole) has a significant relationship with altitude. However, the effect of endogenous and exogenous factors on secondary metabolites biosynthesis -at the same time- makes the evaluation of altitude effect difficult.

\section{Evaluation of antifungal activity}

Among plant extracts, essential oils are the most difficult to be analyzed for antimicrobial activity, because of their limited yield, less-stability, less-solubility in media and their complex composition (Lahlou, 2004). Antimicrobial activities reported in the literature have been evaluated with diverse sets of methodologies, degrees of sensitivity, amount of test-compounds and microbial strains, often difficult to compare (Valgas, et al., 2007). Many laboratories have modified antimicrobial evaluation methods for specific samples, such as essential oils and non-polar extracts and these modifications became impossible to directly compare results (Scorzoni, et al., 2007).

It's well known that inoculum size and antimicrobial quantity influence the efficacy of antimicrobials (Cerero, et al., 2010; Xie, et al., 2017). The effect of inoculum density is observed to be strain dependent (Bedenic, et al., 2001). It has been concluded that the extent of antifungal effect varied depending on the levels of EO used in the experiment (Ozkan \& Chalchat, 2008). Thus, the use of RGR principle in relation to Inhib\%, mycelia inoculum and EO volume gives more opportunity to compare EO effect on filamentous fungi.

The principle of radial growth calculation is based on the diameter of control growth covering the Petri dish, in our case after 10 days. However, we preferred to evaluate the effect after 7-day incubation as well, to calculate the progression of antifungal effect through two periods of time.

\section{Antifungal activity of $\boldsymbol{R}$. officinalis EO on Foa}

The date palm fusariosis caused by Foa presents a serious problem for desertic regions, especially in Algeria and Morocco. The development of efficient treatment is more than necessary to protect the oases. 
Table 2. Effect of essential oils from Rosmarinus officinalis L. on Fusarium oxysporum f. sp. albedinis expressed as GR, Inhib\% and RGR using the micro-atmosphere and direct contact methods.

\begin{tabular}{|c|c|c|c|c|c|c|}
\hline Method & $\mathrm{EO}^{\mathrm{a}}$ part & $\begin{array}{c}\text { Incubation } \\
\text { (days) }\end{array}$ & $\begin{array}{l}\text { EO volume } \\
(\mu \mathrm{L})\end{array}$ & $\begin{array}{c}\mathrm{GR}^{\mathrm{b}} \\
\text { (mm/day) }\end{array}$ & Inhib \%c & $\begin{array}{c}\text { RGR }^{d} \\
\left(\% \cdot \mathrm{mm}^{-1} \cdot \mu \mathrm{L}^{-1}\right)\end{array}$ \\
\hline \multirow{16}{*}{ Micro-atmosphere } & \multirow{8}{*}{ Leaves } & \multirow{4}{*}{7} & 10 & $8.57 \pm 0.17$ & $6.61 \pm 1.80$ & 0.066 \\
\hline & & & 20 & $7.95 \pm 0.05$ & $13.36 \pm 0.52$ & 0.067 \\
\hline & & & 30 & $7.19 \pm 0.13$ & $21.66 \pm 1.37$ & 0.072 \\
\hline & & & 40 & $6.90 \pm 0.13$ & $24.77 \pm 1.37$ & 0.062 \\
\hline & & \multirow{4}{*}{10} & 10 & $7.90 \pm 0.06$ & $6.51 \pm 0.68$ & 0.065 \\
\hline & & & 20 & $7.63 \pm 0.09$ & $9.66 \pm 1.04$ & 0.048 \\
\hline & & & 30 & $7.30 \pm 0.12$ & $13.61 \pm 1.37$ & 0.045 \\
\hline & & & 40 & $7.20 \pm 0.12$ & $14.79 \pm 1.37$ & 0.037 \\
\hline & \multirow{8}{*}{ Stem } & \multirow{4}{*}{7} & 10 & $8.62 \pm 0.13$ & $6.09 \pm 1.37$ & 0.061 \\
\hline & & & 20 & $8.05 \pm 0.05$ & $12.32 \pm 0.52$ & 0.062 \\
\hline & & & 30 & $8.00 \pm 0.08$ & $12.84 \pm 0.90$ & 0.043 \\
\hline & & & 40 & $7.28 \pm 0.08$ & $20.62 \pm 0.90$ & 0.052 \\
\hline & & \multirow{4}{*}{10} & 10 & $7.80 \pm 0.06$ & $7.69 \pm 0.69$ & 0.077 \\
\hline & & & 20 & $7.70 \pm 0.06$ & $8.88 \pm 0.69$ & 0.044 \\
\hline & & & 30 & $7.60 \pm 0.06$ & $10.06 \pm 0.69$ & 0.034 \\
\hline & & & 40 & $7.37 \pm 0.09$ & $12.82 \pm 1.04$ & 0.032 \\
\hline \multirow{16}{*}{ Direct contact } & \multirow{8}{*}{ Leaves } & \multirow{4}{*}{7} & 10 & $5.52 \pm 0.17$ & $39.82 \pm 1.87$ & 0.398 \\
\hline & & & 20 & $4.76 \pm 0.17$ & $48.12 \pm 1.87$ & 0.241 \\
\hline & & & 30 & $3.28 \pm 0.38$ & $64.20 \pm 4.11$ & 0.214 \\
\hline & & & 40 & $3.19 \pm 0.13$ & $65.24 \pm 1.38$ & 0.163 \\
\hline & & \multirow{4}{*}{10} & 10 & $6.30 \pm 0.06$ & $25.44 \pm 0.68$ & 0.254 \\
\hline & & & 20 & $5.57 \pm 0.12$ & $34.12 \pm 1.42$ & 0.169 \\
\hline & & & 30 & $4.93 \pm 0.20$ & $41.62 \pm 2.40$ & 0.139 \\
\hline & & & 40 & $4.37 \pm 0.18$ & $48.32 \pm 2.09$ & 0.121 \\
\hline & \multirow{8}{*}{ Stem } & \multirow{4}{*}{7} & 10 & $5.67 \pm 0.17$ & $38.26 \pm 1.87$ & 0.383 \\
\hline & & & 20 & $3.95 \pm 0.42$ & $56.95 \pm 4.61$ & 0.285 \\
\hline & & & 30 & $4.14 \pm 0.16$ & $54.87 \pm 1.80$ & 0.183 \\
\hline & & & 40 & $3.19 \pm 0.37$ & $65.24 \pm 4.05$ & 0.163 \\
\hline & & \multirow{4}{*}{10} & 10 & $6.40 \pm 0.06$ & $24.26 \pm 0.68$ & 0.243 \\
\hline & & & 20 & $5.63 \pm 0.12$ & $33.33 \pm 1.42$ & 0.167 \\
\hline & & & 30 & $4.87 \pm 0.24$ & $42.41 \pm 2.84$ & 0.141 \\
\hline & & & 40 & $4.00 \pm 0.36$ & $52.66 \pm 4.27$ & 0.132 \\
\hline
\end{tabular}

aEssential oil, bGrowth rate, cPercentage of growth inhibition (Inhib \% values were calculated referred to radial growth of negative control. The radial growth of negative control was: $64.25 \pm 0.75 \mathrm{~mm}$ (7 days of incubation); $84.50 \pm 0.29 \mathrm{~mm}$ (10 days of incubation), ${ }^{\mathrm{d}}$ Relative growth reduction.

Best inhibitory activity of Foa was observed for $10 \mu \mathrm{L}$ of EOs after 7 days incubation using direct contact method (leaves: $R G R=0.398$; stem: $R G R=0.383$ ). The comparison of Inhib\% values between the two periods 
shows a significant decrease from 7 to 10 days $(p<0.05)$. This effect may be explained by the development of resistance mechanism through production of metabolites or enzymes by the fungus to detoxify the antifungal compounds in EO. Ozcan and Chalchat (2008) showed that EO from R. officinalis leaves inhibits $F$. oxysporum after 7 days but no significant inhibition was observed after 10 days. When we link this result with the EO quantity, the increase of EO volume in contact with Foa gave more brake to Foa growth. Farooq et al. (2002) present this phenomenon of detoxification by plant pathogenic fungus. (Table 2)

The antifungal activity of our essential oil might be related to their monoterpenes components which constitute dominant class of compounds in both leaves and stem, with oxygenated monoterpenes (84.9\%, $52.4 \%)$ and monoterpenes hydrocarbons $(12.2 \%, 8.4 \%)$ respectively. Besides a variety of biological activities of monoterpenes, EOs containing high amounts of oxygenated monoterpenes have also been reported to be important antifungal agents (Burt, 2004; Farooq, et al., 2002; Dias, et al., 2017; Danielli, et al., 2019). In addition, it is possible that antifungal activity of $R$. officinalis EO is due to cell membrane disruption by lipophilic compounds (Cowan, 1999).

Inhibition activity can be related to presence of aromatic ring and $\mathrm{OH}$ group (present in the minor compounds such as carvacrol and methyl eugenol) that is known to be reactive forming hydrogen bonds with enzymes causing their inhibition (Velluti, et al., 2003). Thus, antifungal activity may be related to these minor constituents. The synergism between EO constituents is among probable antifungal effect observed in this study.

Lee et al. (2007) demonstrated that F. oxysporum is inhibited by commercial EOs with Inhib\% values 57 to $76 \%$ using micro-atmosphere principle. However, the inoculum size was presented as plugs without specification of diameter. Therefore, it is not possible to compare our results with this study.

Analysis of variance in micro-atmosphere method revealed that effects of all factors on GR and RGR are significant $(p<0.05)$. For $G R$ values, the highest antifungal effect was observed for 7 days of incubation, leaves and $E O$ volume equal to $40 \mu \mathrm{L}(6.90 \pm 0.13 \mathrm{~mm} /$ day). For RGR values, maximum inhibitory activity was observed with stem EO $10 \mu \mathrm{L}(\mathrm{RGR}=0.077)$.

The link between EO amount used and antifungal activity can be explained through two principles. First, for $\mathrm{GR}$ and Inhib\%, the increase in volume permit the increase in EO components responsible for antifungal effect, so $40 \mu \mathrm{L}$ is more efficient than $10 \mu \mathrm{L}$. Second, for RGR, the increase of volume is not related directly to antifungal effect but other parameter is engaged which is fungus quantity (culture diameter). On the other hand, decrease of effect between 7 and 10 days reflects a detoxification phenomenon as explained previously.

The highest effects were observed for direct contact technique. This may be due to the fact that microatmosphere technique permits to only highly volatile compounds to act on Foa (Stupar, et al., 2014). Thus, the antifungal effect using this method is underestimated. However, the micro-atmosphere method has a positive point related to low contamination risk because there is no direct contact between EO and medium.

The results presented in (Table 2) showed a strong correlation among couples $R G R /$ method ( $r=0.80$ ), Inhib\%/method ( $r=0.86), G R /$ method $(r=-0.88)$ and Inhib\%/GR ( $r=-0.99)$. A moderate correlation was observed among couples RGR/Inhib\% $(r=0.62)$ and $R G R / G R(r=-0.60)$. No correlation was observed among others. 
The effect of part used (leaves, stem) was more significant in direct contact method than microatmosphere one $(p<0.05)$. This may be due to the specificity of direct contact method which facilitates the contact between EOs components and Foa.

If we use only Inhib\% values, the best effect was observed for $40 \mu \mathrm{L}$ EO from stem and leaves using direct contact method after 7-day incubation (65.24\% for both). However, using RGR values, the efficient effect was observed for $10 \mu \mathrm{L} E O$ from leaves and stem using direct contact method after 7-day incubation $(0.398$ and 0.383 , respectively). Among the problems related to antifungal effect evaluation is the high assay dosage that may lead to overestimation (Scorzoni, et al., 2007). Thus, the evaluation of antifungal effect without referring to dose used is not sufficient to talk about efficacy. The RGR values reflect the effectiveness of $1 \mu \mathrm{L}$ of EO in the presence of $1 \mathrm{~mm}$ of mycelial inoculums. Therefore, RGR is more suitable to reflect the effect of this EO on Foa. (Table 2)

Its common knowledge that $R$. officinalis is rich in natural products with interesting biological activities. This is the first report on $R$. officinalis EO from Algerian West highlands as source of potential antifungal compounds against Foa.

The GC/MS analysis has demonstrated the richness of this EO in monoterpenes in both leaves and stem. Eucalyptol (1,8-Cineole) was the main component which classifies this EO as 1,8-cineole chemotype.

R. officinalis EOs has presented an important antifungal effect against Foa in first stage. Best inhibitory activity against Foa was determined after 7-day incubation using direct contact method ( $R G R=0.398$; $R G R=383$ ) with EOs from leaves and stem, respectively. Antifungal effect is probably due to the major compounds in the EO (oxygenated and hydrocarbons monoterpenes) or to synergism between constituents. However, it seems that Foa has developed a kind of resistance mechanism. This resistance may be related to detoxification phenomenon. RGR evaluation allows focusing on the efficient dose to avoid insignificant higher doses and work on other parameters to increase effect.

To the best of our knowledge, this is the first report of antifungal activity of $R$. officinalis EO (collected from West highlands of Algeria) on the causal agent of Bayoud disease. The obtained results shed the light on the possibility to use $R$. officinalis EO as source of treatment against Foa by proceeding with further advanced studies.

\section{Conclusion}

Upcoming new insights may focus on major compounds in this EO, especially 1,8 -cineole, to develop efficient treatment. Further in vivo experiments are needed to be performed.

\section{ACKNOWLEDGMENT}

The authors would like to thank DGRSDT (MESRS, Algeria) for financial support.

\section{CONFLICTS OF INTEREST}

The authors have no conflicts of interest to declare.

\section{REFERENCES}

Adams, RP. (Ed.). (2007). Identification of essential oils by gas chromatography/mass spectrometry (4 ${ }^{\text {th }}$ ed.). Carol Stream, IL: Allured Pub. Corp.

Andrade, J.M., Faustino, C., Garcia, C., Ladeiras, D., \& Reis, C.P. (2018). Rosmarinus officinalis L.: An update review of its phytochemistry and biological activity. Future Science OA, 4(4), FSO283. 
Babushok, V.I., Linstrom, P.J., \& Zenkevich, I.G. (2011). Retention indices for frequently reported compounds of plant essential oils. Journal of Physical and Chemical Reference Data, 40(4), 1-47.

Barra, A. (2009). Factors affecting chemical variability of essential oils: A review of recent developments. Natural Product Communications, 4(8), 1147-1154.

Bedenic, B., Beader, N., \& Zagar, Z. (2001). Effect of inoculum size on the antibacterial activity of cefpirome and cefepime against Klebsiella pneumonia strains producing SHV extended-spectrum $\beta$-lactamases. Clinical Microbiology and Infection, 7(11), 626-635.

Belhi, Z., Boulenouar, N., Cheriti, A., \& Marouf, A. (2020). Antifungal and anti-cellulases activity of Limoniastrum feei extracts to promote Bayoud disease treatment using bioautography. Cogent Food and Agriculture, 6(1), 1-12.

Benabed, K.H., Gourine, N., Ouinten, M., Bombarda, I., \& Yousfi, M. (2017). Chemical composition, antioxidant and antimicrobial activities of the essential oils of three Algerian Lamiaceae species. Current Nutrition and Food Science, 13(2), 97-109.

Boix, Y.F., Pimentel, V.C., Antunes, D.A.C., De Oliveira, A.R.D.C., Sato, A., \& Salgueiro, L.C.L. (2011). Glandular trichomes of Rosmarinus officinalis L.: anatomical and phytochemical analyses of leaf volatiles. Plant Biosystems, 145(4), 848-856.

Boukhobza, Z., Cheriti, A., Boulenouar, N., Djeradi, H., Kacimi, El-Hassani, M., Lahreche, M.B., \& Sekkoum, Ka. (2020). Brocchia cinerea essential oil from Brezina (Algerian Sahara): Chemical characterization and antibacterial activity. Journal of Chemical Science and Chemical Engineering, 1(1), 19-24.

Boulenouar, N., Marouf, A., \& Cheriti, A. (2009). Effect of some poisonous plants on Fusarium oxysporum f. sp. albedinis. Journal of Biological Sciences, 9(6), 594-600.

Boulenouar, N., Marouf, A., \& Cheriti, A. (2011). Antifungal activity and phytochemical screening of extracts from phoenix dactylifera L. cultivars. Natural Products Research, 25(20), 1999-2002.

Boulenouar, N., Marouf, A., Cheriti, A., \& Belboukhari, N. (2012). Medicinal plants extracts as source of antifungal agents against Fusarium oxysporum f. sp. albedinis. Journal of Agricultural Science and Technology, 14, $659-669$.

Boulenouar, N., Marouf, A., \& Cheriti, A. (2014). Direct bioautography for antifungal activity measurement "case of Bayoud disease". PhytoChem and Biosubstances Journal, 8(1), 33-37.

Boutabia, L., Telailia, S., Bouguetof, I., Guenadil F., \& Chefrour A. 2016. Composition chimique et activité antibactérienne des huiles essentielles de Rosmarinus officinalis L. de la région de Hammamet (Tébessa-Algérie). Bulletin de la Société Royale des Sciences de Liège, 85, 174-189.

Boutekedjiret, C., Bentahar, F., Belabbes, R., \& Bessiere, J. (1998). The essential oil from Rosmarinus officinalis, L. Journal of Essential Oil Research, 10, 680-682.

Bruneton, J. (Ed.). (1999). Pharmacognosy, phytochemistry, medicinal plants ( ${ }^{\text {nd }}$ ed.). Paris, France: Tec \& Doc.

Burt, S. (2004). Essential oils: Their antibacterial properties and potential applications in foods, a review. International Journal of Food Microbiology, 94, 223-253.

Carvalho, R.N. Jr., Moura, L.S., Rosa, P.T.V., \& Meireles, M.A.A. (2005). Supercritical fluid extraction from rosemary (Rosmarinus officinalis): Kinetic data, extract's global yield, composition, and antioxidant activity. Journal of Supercritical Fluids, 35(3), 197-204.

Celiktas, O.Y., Kocabas, E.E.H., Bedir, E., Sukan, F.V., Ozek, T., \& Baser, K.H.C. (2007). Antimicrobial activities of methanol extracts and essential oils of Rosmarinus officinalis, depending on location and seasonal variations. Food Chemistry, 100(2), 553-559.

Cerero, L.L., Picon, E., Morillo, C., Hernandez, J.R., Docobo, F., Pachon, J., Rodriguez-Bano, J., \& Pascual, A. (2010). Comparative assessment of inoculum effects on the antimicrobial activity of amoxycillin-clavulanate and piperacillin- 
tazobactam with extended-spectrum $\beta$-Lactamase-producing and extended-spectrum $\beta$-lactamase-non-producing Escherichia coli isolates. Clinical Microbiology and Infection, 16(2), 132-136.

Chalchat, J.C., Garry, R.P., Michet, A., Benjilali, B., \& Chabart, J. (1993). Essential oils of rosemary (Rosmarinus officinalis L.): The chemical composition of oils of various origins (Morocco, Spain, France). Journal of Essential Oil Research, 5, 613-618.

Cheriti, A., Rouissat, A., Sekkoum, K., \& Balansard, G. (1995). Plants of traditional pharmacopeia in El-Bayadh region (Algeria). Fitoterapia, 66(6), 525-538.

Cheriti, A. (2000). Medicinal Plants of Bechar Region, South-West of Algeria: Ethnopharmacological study. CRSTRA Report, pp. 3-11.

Cowan, M.M. (1999). Plant products as antimicrobial agents. Clinical Microbiology Reviews, 12(4), 564-582.

Dalili, A., Bakhtiari, S., Barari, H., \& Aldaghi, M. (2015). Effect of some fungicides against the growth inhibition of Sclerotinia sclerotiorum mycelia compatibility groups. Journal of Plant Protection Research, 55(4), 354-361.

Danielli, L.J., de Souza, T.J.T., Maciel, A.J., Ferrão, M.F., Fuentefria, M.A., \& Apel, M.A. (2019). Influence of monoterpenes in biological activities of Nectandra megapotamica (Spreng.) Mez Essential Oils. Biomolecules, 9(3), 112.

Diab, Y., Auezova, L., Chebib, H., Chalchat, J.C., \& Figueredo, G. (2002). Chemical composition of Lebanese rosemary (Rosmarinus officinalis L.) essential oil as a function of the geographical region and the harvest time. Journal of Essential Oil Research, 14(6), 449-452.

Dias, N., Dias, M.C., Cavaleiro, C., Sousa, M.C., Lima, N., \& Machado, M. (2017). Oxygenated monoterpenes-rich volatile oils as potential antifungal agents for dermatophytes. Natural Products Research, 31(4), 460-464.

Djeddi, S., Bouchenah, N., Settar, I., \& Skaltsa, H. D. 2007. Composition and antimicrobial activity of the essential oil of Rosmarinus officinalis from Algeria. Chemistry of Natural Compounds, 43(4), 487-490.

Fadel, H.H.M., \& El-Massry, K.F. (2000). Rosmarinus officinalis L.: effect of drying on the volatile oil of fresh leaves and antioxidant activity of their extracts. Journal of Essential Oil-Bearing Plants, 3(1), 5-19.

Durak, Z.E., Cubukcu, H.K., Buber, S., Kocoaglu, H., \& Durak, I. (2016). Aqueous extracts of Rosmarinus officinalis, Urtica diocia, and soybean exert different effects on adenosine deaminase activity in cancerous and noncancerous human gastric and colon tissues. Journal of Health Research and Reviews, 3(1), 24-27.

Farooq, A., Choudhary, M.I., Atta-ur-Rahman, \& Tahara, S. (2002). Detoxification of terpinolene by plant pathogenic fungus Botrytis cinerea. Zeitschrift für Naturforschung C, 57(9-10), 863-866.

Fellah, O., Hameurlaine, S., Bourenane, N., Gherraf, N., Zellagui, A., Abidi, A., Tahar, A., Altun, M., Demirtas, I., \& Yagioglu, A.S. (2018). Climatic factors as quality determinant of essential oils and phenolics in Rosmarinus officinalis L. (Lamiales Lamiaceae) collected from three geographic areas in Algeria. Biodiversity Journal, 9(3), 187-194.

Figueiredo, A.C., Barroso, J.G., Pedro, L.G., \& Scheffer, J.J.C. (2008). Factors affecting secondary metabolite production in plants: volatile components and essential oils. Flavour and Fragrance Journal, 23(4), 213-226.

Ghazi, R., Boulenouar, N., Cheriti, A., Reddy, K., \& Govender, P. (2020). Bioguided fractionation of Citrullus colocynthis extracts and antifungal activity against Fusarium oxysporum f.sp. albedinis. Current Bioactive Compdounds, 16(3), 302307.

Hcini, K., Sotomayor, J.A., Jordan, M.J., \& Bouzid, S. (2013). Chemical composition of the essential oil of Rosemary (Rosmarinus officinalis L.) of Tunisian origin. Asian Journal of Chemistry, 25(5), 2601-2603.

Isikber, A.A., Alma, M.H., Kanat, M., \& Karci, A. (2006). Fumigant toxicity of essential oils from Laurus nobilis and Rosmarinus officinalis against all life stages of Tribolium confusum. Phytoparasitica, 34, 167. 
Jawad, A.M., Allawi, A.K., \& Ewadh, H.M. (2018). Essential oils of rosemary as antimicrobial agent against three types of bacteria. Medical Journal of Babylon, 15, 53-6.

KIbar, B. \& Peksen A. (2011). Mycelial growth requirements of Lactarius pyrogalus and Lactarius controversus. African Journal of Microbiology Research, 5(28), 5107-5114.

Kumar, A., Niranjan, A., Lehri, A., Srivastava, R.K., \& Tewari, S.K. (2016). Effect of geographical climatic conditions on yield, chemical composition and carbon isotope composition of nagarmotha (Cyperus scariosus R. Br.) essential oil. Journal of Essential Oil-Bearing Plants, 19, 368-373.

Lahlou, M. (2004). Methods to study the phytochemistry and bioactivity of essential oils. Phytotherapy Research, 18, 435-448.

Lee, S.O., Choi, G.J., Jang, K.S., Lim, H.K., Cho, K.Y., \& Kim, J-C. (2007). Antifungal activity of five plant essential oils as fumigant against postharvest and soilborne plant pathogenic fungi. Plant Pathology Journal, 23(2), 97-102.

Mata, A.T., Proença, C., Ferreira, A.R., Serralheiro, M.L.M., Nogueira, J.M.F., \& Araújo, M.E.M. (2007). Antioxidant and antiacetylcholinesterase activities of five plants used as Portuguese food spices. Food Chemistry, 103(3), 778-786.

Mekonnen, A., Yitayew, B., Tesema, A., \& Taddese, S. (2016). In vitro antimicrobial activity of essential oil of Thymus schimperi, Matricaria chamomilla, Eucalyptus globulus, and Rosmarinus officinalis. International Journal of Microbiology, 1-8.

Mekonnen, M., \& Manahile, B. (2017). Assessment of yield loss in Rosemary (Rosmarinus officinali L.) and Sage (Salvia officinalis L.) plants caused by Fusarium oxysporum. African Journal of Agricultural Research, 12(19), 1669-1673.

Napoli, E.M., Curcuruto, G., \& Ruberto, G. (2010). Screening of the essential oil composition of wild Sicilian rosemary. Biochemical Systematics and Ecology, 38(4), 659-670.

Ozcan, M.M., \& Chalchat, J-C. (2008). Chemical composition and antifungal activity of Rosemary (Rosmarinus officinalis L.) oil from Turkey. International Journal of Food Sciences and Nutrition, 59(7-8), 691-698.

Rahmouni, A., Saidi, R., Khaddor, M., Pinto, E., Gomes, E.D.S.J.C., \& Maouni, A. (2019). Chemical composition and antifungal activity of five essential oils and their major components against Fusarium oxysporum f. sp. albedinis of Moroccan palm tree. Euro-Mediterranean Journal of Environmental Integration, 4(1), 1-9.

Rao, B.R.R., Syamasundar, K.V., \& Patel, R.P. (2014). Effect of method of distillation on the yield and chemical composition of Artemisia annua essential oil. Journal of Essential Oil Research, 26, 486-491.

Sabahi, M., El Hassouni, A., Tahani, A., \& El Bachiri, A. (2020). Altitude effect on the chemical composition and antioxidant activity of Rosemary in the region of Talsint (Morocco). Moroccan Journal of Chemistry, 8(4), 866-875.

Salido, S., Altarejos, J., Nogueras, M., Sanchez, A., \& Luque, P. (2003). Chemical composition and seasonal variations of rosemary oil from southern Spain. Journal of Essential Oil Research, 15(1), 10-14.

Scorzoni, L., Benaducci, T., Almeida, A.M.F., Silva, D.H.S., Bolzani, V.Ds., \& Gianinni, M.G.S.M. (2007). The use of standard methodology for determination of antifungal activity of natural products against medical yeasts Candida $\mathrm{sp}$ and Cryptococcus sp. Brazilian Journal of Microbiology, 38, 391-397.

Serralutzu, F., Stangoni, A., Amadou, B., Tijan, D., Re, G.A., Dore, A., \& Bullitta, S. (2020). Essential oil composition and yield of a Rosmarinus officinalis $L$. natural population with an extended flowering season in a coastal Mediterranean environment and perspectives for exploitations. Genetic Resources and Crop Evolution, 67(7), 1777-1793.

Shaaban, H.A.E., El-Ghorab, A.H., Shibamoto, T. (2012). Bioactivity of essential oils and their volatile aroma components: Review. Journal of Essential Oil Research, 24, 203-212.

Singh, S., Haider, S.Z., Chauhan, N.K., Lohani, H., Sah, S., \& Yadav, R.K. (2014). Effect of time of harvesting on yield and quality of Melissa officinalis L. in Doon valley, India. Indian Journal of Pharmaceutical Sciences, 76, 449-452. 
Stupar, M., Grbic M-Lj., Dzamic, A., Unkovic, N., Ristic, M., Jelikic, A., \& Vukojevic, J. (2014). Antifungal activity of selected essential oils and biocide benzalkonium chloride against the fungi isolated from cultural heritage objects. South African Journal of Botany, 93, 118-124.

Valgas, C., Souza, S.M., Smania, E.F.A., \& Smania, A. (2007). Screening methods to determine antibacterial activity of natural products. Brazilian Journal of Microbiology, 38, 369-380.

Velluti, A., Sanchis, V., Ramos, A.J., Edigo, J., \& Marin, S. (2003). Inhibitory effect of cinnamon, clove, lemongrass, oregano and palmarose essential oils on growth and fumonisin B1 production by Fusarium proliferatum in maize grain. International Journal of Food Microbiology, 89, 145-154.

Zaouali, Y., Chograni, H., Trimech, R., \& Boussaid, M. (2013). Changes in essential oil composition and phenolic fraction in Rosmarinus officinalis L. var. typicus Batt. organs during growth and incidence on the antioxidant activity. Industrial Crops and Products, 43(1), 412-419. 